\title{
Author Correction: Structure of the yeast Swi/Snf complex in a nucleosome free state
}

\author{
Chengcheng Wang (D), Zhouyan Guo (D), Xiechao Zhan (D), Fenghua Yang, Mingxuan Wu \& Xiaofeng Zhang (1)
}

Correction to: Nature Communications https://doi.org/10.1038/s41467-020-17229-x, published online 7 July 2020

The original version of this Article contained an error in Fig. 3c, where residue Snf6_F103 was mislabelled as Snf6_F102. The Article also contained an error describing Fig. $3 c$ in the "Results" section, which incorrectly referred to Phe80 instead of Phe103. The correct text should read 'Arg84, the N-terminal residue of Snf6_loop 1, interacts with Asp578 from the HSA helix through hydrogen bonds (Fig. 3b), while the C-terminal residue Phe103 forms $\Pi$ stacking with the residue Pro565 from Snf2 (Fig. 3c).'

These errors have been corrected in both the PDF and HTML versions of the Article.

Published online: 06 November 2020

\footnotetext{
(c) (i) Open Access This article is licensed under a Creative Commons Attribution 4.0 International License, which permits use, sharing, adaptation, distribution and reproduction in any medium or format, as long as you give appropriate credit to the original author(s) and the source, provide a link to the Creative Commons license, and indicate if changes were made. The images or other third party material in this article are included in the article's Creative Commons license, unless indicated otherwise in a credit line to the material. If material is not included in the article's Creative Commons license and your intended use is not permitted by statutory regulation or exceeds the permitted use, you will need to obtain permission directly from the copyright holder. To view a copy of this license, visit http://creativecommons.org/licenses/by/4.0/.
}

(C) The Author(s) 2020 